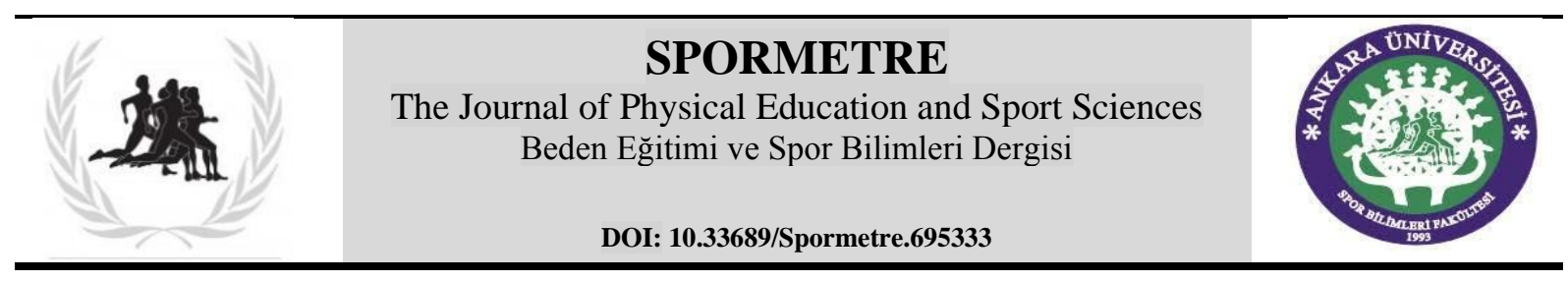

Geliş Tarihi (Received): 27.02.2020

Kabul Tarihi (Accepted): 30.11.2020

Online Yayın Tarihi (Published): 30.12.2020

\title{
YÜKSEK ŞİDDETLİ İNTERVAL ANTRENMANLARIN (HIIT) AEROBİK DAYANIKLILIK VE VÜCUT YAĞ YAKIMI ÜZERİNE ETKİLERİ
}

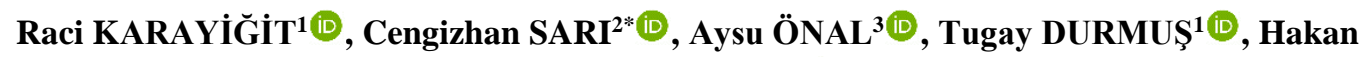 \\ BÜYÜKÇELEBi ${ }^{4}$ (D) \\ ${ }^{1}$ Ankara Üniversitesi, Spor Bilimleri Fakültesi, ANKARA \\ ${ }^{2}$ Muş Alparslan Üniversitesi, Spor Bilimleri Fakültesi, MUŞ \\ ${ }^{3}$ Ankara Üniversitesi, Sağlık Bilimleri Enstitüsü, ANKARA \\ "İnönü Üniversitesi, Spor Bilimleri Fakültesi, MALATYA
}

\begin{abstract}
Öz: Yüksek şiddetli interval antrenmanlar (HIIT) zaman açısından ekonomik olması ve kısa zamanda yüksek performans artışı elde edilmesi sebebiyle son dönemlerde popüler bir antrenman metodu haline gelmiştir. Ayrıca HIIT sportif performans artışının yanı sıra genel sağlı̆̆ı iyileştirici etkileri nedeniyle de antrenman programlarında sıklıkla tercih edilmektedir. Bu çalışmanın amacı, sporda önemli bir antrenman yöntemi olan HIIT'in aerobik dayanıklılık ve vücut yağ yakımı üzerindeki etkilerini incelemektir. Bu nedenle HIIT'in sporcu, sedanter, aşırı kilolu ve obez bireyler üzerinde vücut yağ yakımına ve aerobik dayanıklılığa kronik etkilerini inceleyen 15 adet çalışma derlenmiştir. Konuyla ilgili çalışmalar Web of Science, Scopus, PubMed ve ULAKBİM elektronik veri tabanlarında taranmıştır. Mevcut derleme için incelenen çalışmalarda katılımcıların yaş, cinsiyet, vücut ağırlığı, sporcu veya sedanter olmaları ve fiziksel aktivite düzeyleri ile ilgili bir sınır gözetilmemiştir. Sonuç olarak HIIT etki mekanizması sayesinde hem fiziksel çalışma kapasitesini geliştirmekte hem de vücut yağ yakımını hızlandırmaktadır. İncelenen çalışmalar HIIT’in vücut yağ yakım hızında artış, vücut yağ kütlesinde azalma ve aerobik dayanıklılığı geliştirmek için oldukça etkili bir yöntem olarak kullanılmasını desteklemektedir. HIIT antrenmanlarının kısa zamanda aerobik dayanıklılığı geliştirmesi ve vücut yağ yakımını hızlandırmasından dolayı, bu parametreler üzerinde etkili olduğu açıkça gözlemlenmektedir.
\end{abstract}

Anahtar Kelimeler: Aerobik dayanıklılık, HIIT, obezite, vücut yağ yakımı, yüksek şiddetli interval antrenman

\section{THE EFFECTS OF HIGH-INTENSITY INTERVAL TRAINING (HIIT) ON AEROBIC ENDURANCE AND BODY FAT BURNING}

\begin{abstract}
High-intensity interval training (HIIT) has become a popular training method in recent periods because it is economical in terms of time and the high-performance increase is achieved in a short time. In addition, HIIT is often preferred in training programs due to its increase in sports performance as well as its overall health-improving effects. The aim of this study is to examine the effects of HIIT, an important training method in sports, on aerobic endurance and body fat burning. Therefore, 15 studies have been compiled examining the chronic effects of HIIT on body fat burning and aerobic endurance in athletes, sedentary, overweight and obese individuals. Studies on the subject have been investigated in Web of Science, Scopus, PubMed and ULAKBIM electronic databases. In the studies examined for the current review, there was no limit to the age, gender, body weight, whether they were athletes or sedentary, and their level of physical activity. As a result, thanks to HIIT mechanism of action, it increases both the physical working capacity and body fat burning. The reviewed studies support the use of HIIT as a highly effective method for increasing body fat burning rate, decreasing body fat mass and improving aerobic endurance. Because HIIT training improves aerobic endurance and body fat burning in a short time, it is clearly observed that it is effective on these parameters.
\end{abstract}

Key Words: Aerobic endurance, HIIT, obesity, body fat burning, high-intensity interval training 


\section{GİRIŞ}

Aerobik dayanıklılık, organizmanın yüklenmeye uzun süreli ve kesintisiz olarak dayanabilme yeteneği olarak tanımlanmaktadır ve aerobik dayanıklılığı geliştirmek yoğun ve uzun süreli bir çalışma programı gerektirmektedir. Bu yüzden çalışma süresi olarak haftanın en az 3 günü, günde en az 45-50 dakikalık dayanıklılık egzersizlerini 8-12 hafta boyunca devam ettirmek gerekmektedir (ACSM, 2014). Dayanıklılık egzersizleri olarak geleneksel devam koşuları kullanılmaktadır. Devam koşularında egzersiz sürekli ve aralıksız uzun süreli yüklenmelerle ve oksijen kullanılarak enerji üretimi olmak şartıyla uygulanmaktadır (Gündüz, 1997). Bu tarz dayanıklılık egzersizleri oldukça fazla zaman almaktadır, bu nedenle aerobik kapasitenin geliştirilmesinde yüksek şiddetli interval antrenmanlar (HIIT, high intensity interval training) daha etkili bir yöntem olarak ortaya çıkmaktadır. İnterval antrenmanın yöntemi belirlenen egzersizlerin belirli aralıklarla tekrar edilmesi şeklinde gerçekleştirilmektedir. İnterval antrenmanın özelliği, yüklenme ve dinlenme ya da yüksek ve düşük şiddette yüklenmelerin sistemli bir şekilde değişimidir. (Revan ve ark., 2008). Bu yöntem, hızlı ve etkili uyum gereksinimini karşılamakta ve aynı zamanda egzersiz için harcanan zamanı kısaltmaktadır. Babraj ve arkadaşları (2009), 2 hafta boyunca toplam 6 seans uygulanan HIIT antrenmanlarının aerobik ve anaerobik kapasiteyi ve buna ilaveten metabolik fonksiyonları önemli derecede geliştirdiğini ortaya koyan çalışmalar olduğunu vurgulamaktadır. HIIT antrenmanları daha kısa zaman harcamasına rağmen orta şiddette sürekli yapılan çalışmalara kıyasla fizyolojik olarak daha etkilidir (Buchheit ve Laursen, 2013) ve maksimal oksijen tüketimi (VO2 ${ }_{\text {maks }}$ ), anaerobik eşik ve kalp atım hacmi gibi parametreler üzerinde hızlı fizyolojik uyumlar sağlamaktadır (Weston ve ark., 2014). Dayanıklılık egzersizleri sadece sportif performansı geliştirmek için değil, genel sağlığ iyileştirici ve kronik hastalıklardan koruyucu etkisi ile de önemli bir konuma sahiptir.

İnsan sağlığına etki eden önemli unsurlardan biri de vücut yağ miktarıdır. Çünkü vücut yağ miktarı obezite ile birebir ilişkili bir kavramdır. HIIT dayanıklılık gelişiminin yanı sıra vücut yağ yakımına olan etkisi bakımından da çok tercih edilen bir antrenman metodudur. Fiziksel inaktivite ve obezitenin kombinasyonu, birçok kronik hastalığı tetiklemektedir ve aşırı kilo/obezitenin dünya çapında ciddi sağlık sorunlarını ortaya çıkardığı, tip 2 diyabet (DM2) ve kardiyovasküler hastalıklar gibi bulaşıcı olmayan hastalıkları geliştirme riskinin olduğu konusunda ciddi kanıtlar bulunmaktadır (Rana ve ark., 2007; Reddigan ve ark., 2011). Egzersiz, kas kütlesi, kilo kaybı ve kardiyo-metabolik sağlığı yaştan bağımsız olarak artırmak için etkili bir uyarandır ve bu nedenle obezite ve obezite ile ilgili hastalıkların artmasına karşı mücadelede önemli bir rol oynayabilmektedir. (Gökdemir ve ark., 2007; Patlar ve ark., 2003; Trapp ve ark. 2008). Dayanıklılık antrenmanlarının vücut kompozisyonuna olan etkileri araştırıldığında yapılan antrenmanların vücut yăg yüzdesi, beden kütle indeksi, toplam vücut ağırlığı ve deri kıvrım kalınlığı üzerinde anlamlı azalmalar sağladığı gözlemlenirken yağsız vücut kütlesinde ve vücut yoğunluğunda da anlamlı artışlar meydana getirdiği ortaya koyulmuştur (Gökdemir ve ark., 2007; Patlar ve ark., 2003; Trapp ve ark., 2008). Obezite, çocukluk ve gençlik çağında oluştuğu zaman hayatın ileri safhalarında birçok kardiyometabolik rahatsızlık oluşumu riskinde artışa sebep olmaktadır. Meydana gelebilecek metabolik ve kardiyovasküler komplikasyonların riskinin azalmasında, obezitenin erken yaşlarda teşhis edilip gereken tedbirlerin alınması önemli bir rol oynamaktadır (Aslan ve Yardımcı, 2017). HIIT uygulamalarının çocuklarda ve gençlerde de beden sağlı̆̆ı üzerinde etkili bir gelişim sağladığı bildirilmektedir (Buchheit ve Laursen, 2013). Çocukların yetişkinlere göre daha düşük dayanıklılık kapasitesine sahip olmasına rağmen çalışmalar, HIIT sırasında çocukların performanslarını ciddi bir yorgunluk olmadan sürdürdüğünü göstermiştir (Sperlich ve ark., 2011). Aşırı kilolu/obez çocuk ve gençlerde fiziksel aktiviteye düzenli katılımın önündeki ana engellerden biri de zaman 
eksikliğidir. HIIT, çocuklarda ve ergenlerde metabolik ve kardiyovasküler sağlığı iyileştirmede zaman açısından etkili bir yöntemdir (Zabinski ve ark., 2003). Son yıllarda yapılan sistematik derlemeler HIIT yönteminin çocuk ve ergenlerde geleneksel antrenman yöntemlerine kıyasla, sağlıkla ilgili parametrelerde daha fazla gelişme sağlayabileceğini vurgulamıştır (Costigan ve ark., 2015; Logan ve ark., 2014). HIIT yöntemi aerobik ve anaerobik kapasite, vücut yağ yakımı, kalp kasılabilirliği, kas kütlesi, endotel fonksiyon, insülin duyarlılığı, bazal metabolizma hızı, glikoz toleransı ve HDL kolesterol artışı sağlarken aynı zamanda sistolik ve diyastolik kan basınc1, açlık kan glikozu, trigliserid, oksidatif stres ve inflamasyonda azalma meydana getirmektedir (Len Kravitz, 2011; Martins ve ark., 2016). Bu çalışmanın amacı, popüler bir antrenman yöntemi olan yüksek şiddetli interval antrenmanların (HIIT), aerobik dayanıklılığa ve vücut yağ yakımına olan etkilerini gösteren bazı araştırmaları incelemektir.

\section{YÖNTEM}

\section{Veri Kaynakları ve Literatür Tarama}

Konuyla ilgili çalışmalar Web of Science, Scopus, PubMed ve ULAKBİM elektronik veri tabanlarında taranmıştır. İlgili konu bu veri tabanlarında Kasım 2019 tarihine kadar araştırılmıştır. Aramalar, "HIIT", "high intensity interval training (yüksek şiddetli aralıklı antrenman, yüksek şiddetli interval antrenman)", "aerobic endurance (aerobik dayanıklılık)", "body fat burning (vücut yă̆ yakımı)", "weight loss (kilo kaybı)", "obese (obezite) ", "body composition (vücut kompozisyonu)", "exercise (egzersiz)", "physical activity (fiziksel aktivite)", ve yukarıda belirtilen anahtar kelimelerin kombinasyonları kullanılarak gerçekleştirilmiştir.

\section{Çalışma Yöntemi ve Dahil Etme Kriterleri}

Mevcut derlemede konuyla ilgili belirlenen 15 çalışma incelenmiştir. İncelenen çalışmalarda kronik etkiler ele alınmıştır. Akut etkiye bakılan çalışmalar, gözlemsel çalışmalar ve hayvan deneyleri bu makaleye dahil edilmemiştir. Mevcut derleme için incelenen çalışmalarda katılımcıların yaş, cinsiyet, vücut ağırlığı, sporcu veya sedanter olmaları ve fiziksel aktivite düzeyleri ile ilgili bir sınır gözetilmemiştir. Katılımcıların HIIT öncesi ve sonrası aerobik dayanıklılık ve vücut yağ yakımı bulguları derlenmiştir.

\section{HIIT VE FİYYLOJIKK MEKANIZMA}

Mitokondride bulunan PGC-1 $\alpha$ (Peroxisome proliferator-activated receptor gamma coactivator 1-alpha) reseptörünün aktivasyonu yüksek şiddetli egzersizler sonucunda daha fazla etkilenmektedir. PGC-1 $\alpha$ reseptörü daha aktif hale geldiğinde ise ATP üretimi artmaktadır. PGC-1 $\alpha$ 'nın aktif hale gelip artması ile mRNA mitokondri içerisinde daha etkin olmaktadır, bu da mitokondrial adaptasyonu hızlandırmaktadır (Gibala ve Gee, 2008; Little, 2010). Yüksek şiddetli antrenmanlar bu reseptörün mitokondrideki aktivasyonunu artırarak daha fazla enerji üretimi sağlamaktadır. Bunun sonucunda iskelet kasının oksidasyon kapasitesi artmaktadır ve maksimal egzersiz seviyesi gelişmektedir (Gibala ve Gee, 2008; Little, 2010). PGC-1 $\alpha$ reseptör aktivasyonunun 6 hafta gerçekleştirilen HIIT antrenmanları ile \%100, 2 haftalık antrenmanlar ile \%25 artırıldığı bildirilmektedir (Gibala ve Gee, 2008; Little, 2010). Gibala ve ark., (2009) altı sağlıklı aktif genç erkek üzerinde yaptıkları çalışmada, kısa süreli yoğun interval egzersizin insan iskelet kasında PGC-1 $\alpha$ ekspresyonunu artırdığını gözlemlemişlerdir.

Egzersiz iskelet kasında PGC-1 $\alpha$ aktivasyonunu artırmaktadır. Bu da kaslarda fibronektin tip III domain 5 (FNDC5) isimli membran proteininin ekspresyonunu artırmaktadır ve FNDC5' in içerisinde bulunan irisin hormonu aktif hale gelerek dolaşıma salınmaktadır. İrisinin, iskelet 
kasından salgılanan bir miyokin olduğu ve düzenli fiziksel aktivite yapıldığı zaman bireyleri metabolik hastalıklardan koruduğu bildirilmiştir (Schumacher ve ark., 2013). Bu miyokinin, kaslarda fibronektin tip III domain 5 (FNDC5) adında bir membran proteini olduğu ve irisinin FNDC5 proteininin proteolitik bir ürünü olduğu anlaşılmıştır (Norheim, 2014). İrisin, glikoz homeostazını, lipit profilini ve metabolik parametreleri geliştirmektedir. Ayrıca kas dokusu ile birlikte karaciğerde kahverengileşmeyi sağlayarak yağ dokusu üzerinde etkili olmaktadır (Perakakis, 2017). İrisin, iskelet kası, karaciğer, pankreas, kalp, yağ ve beyinde bulunan belirli hücrelerin işlevini saptamak amacıyla sinyal gönderen güçlü bir habercidir (Gizaw, 2017). Dolaşıma salınan irisin, beyaz yağ dokularına bilinmeyen bir reseptör ile bağlanarak bu dokuların genetik profilini değiştirmekte ve beyaz yağ dokuları kahverengi yağ dokularına dönüşmektedir. Beyaz yağ dokularının kahverengileşmesi mitokondrial yoğunluğun ve oksijen tüketiminin artırılması ile bağlantılıdır. Kahverengileşme yağ dokularının enerji harcama profilini artırmakta ve metabolizma üzerinde olumlu etkiler sağlamaktadır (CastilloQuan, 2012).

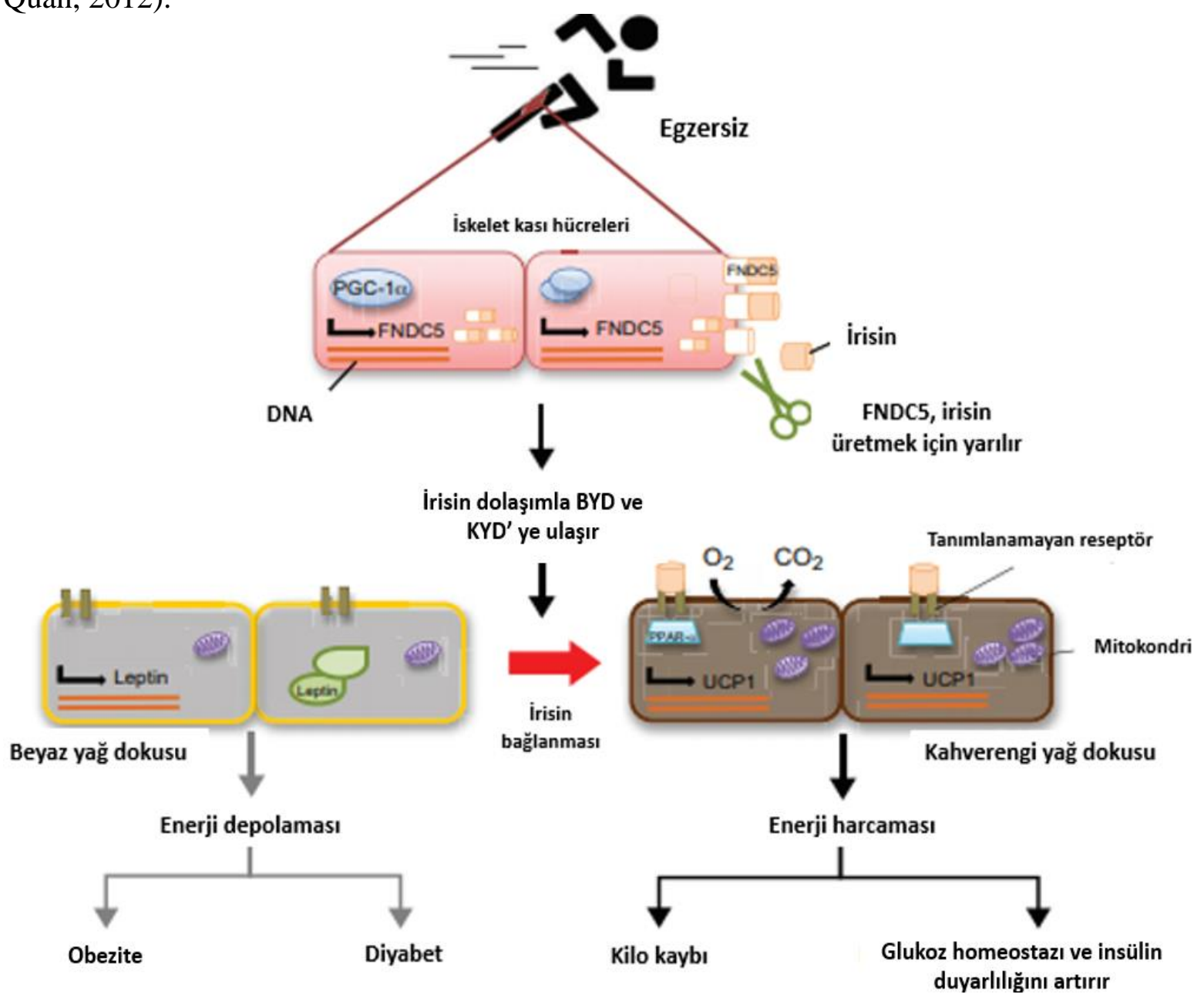

*Castillo-Quan, 2012.

\section{HIIT ANTRENMAN YÖNTEMLERİ}

HIIT antrenmanlarının birçok farklı yöntemi mevcuttur. Temel olarak interval antrenmanlar, yüklenme ve dinlenme sürelerinin kısa [6-30sn \%85-100 maksimal kalp atım hızı ( $\left.\mathrm{KAH}_{\text {maks }}\right)$ ] olduğu yoğun intervaller ile yüklenme ve dinlenme süresinin uzun (1-5dk \%60-80 KAH maks) olduğu yaygın interval yöntemleri ele alınarak birçok farklı antrenman metodu ortaya çıkmıştır. Bunlar bisiklet ergometresi yöntemi, Tabata ve Gibala yöntemleri, dairesel ağırlık (circuit) yöntemi, insanity yöntemi, yürüme koşma ve suda yapılan yüzme yöntemleri olarak 
gerçekleştirilmektedir. Ayrıca HIIT antrenmanları kuvvet egzersizleri ile de kombine olarak uygulanabilmektedir.

\section{KONUYLA İLGİLİ BAZI ÇALIŞMALAR}

HIIT uygulamaları sporcularda, sedanterlerde, çocuklarda, gençlerde ve aşırı kilolu/obez kişilerde dayanıklılık ve vücut yağ yakımı bakımından olumlu gelişmeler göstermiştir (Tablo $1)$.

Impellizzeri ve ark. (2006) kırk genç futbolcuya haftanın iki günü toplam sekiz haftalık HIIT

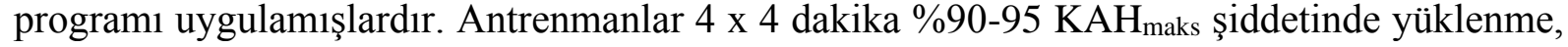

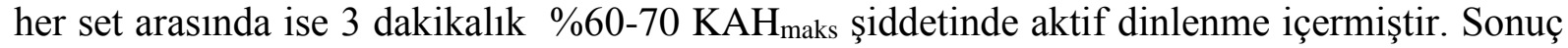
olarak genç futbol oyuncularına uygulanan sekiz haftalık HIIT programı oyuncuların VO2 ${ }_{\text {maks, }}$ bireysel anaerobik eşik ve futbola özgü Ekblom testi performans değerlerinde artış meydana getirmiştir.

HIIT'in genç kadınlarda yağ kaybı ve açlık insülin seviyelerine etkisini inceleyen Trapp ve ark. (2008) haftada üç gün olmak üzere on beş hafta süren HIIT programında kırk beş genç kadına, bisiklet ergometresi kullanarak 20 dakika tamamlanacak şekilde 60 tane 8 saniye sprint, 12 saniye aktif dinlenme şeklinde egzersiz yaptırmışlardır. On beş haftanın sonunda toplam kırk beş egzersizi tamamlayan genç kadınlarda bacak ile gövde derialtı yă̆ oranında ve vücut

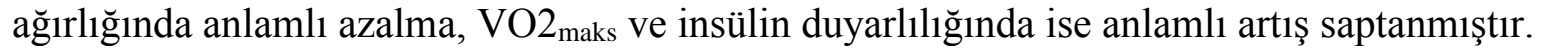

Dokuz genç erkek sporcu üzerinde araştırma yapan Sperlich ve ark. (2011), beş hafta boyunca toplam on üç seans $\mathrm{KAH}_{\text {maks' }}$ 'n \%90'1nda HIIT uygulamışlardır. Sonuç olarak grafik 1'de gösterildiği gibi $\mathrm{VO} 2_{\text {maks }}$ ve sprint performansında artış, $1000 \mathrm{~m}$ koşu zamanında azalma gözlemlenmiştir.

A
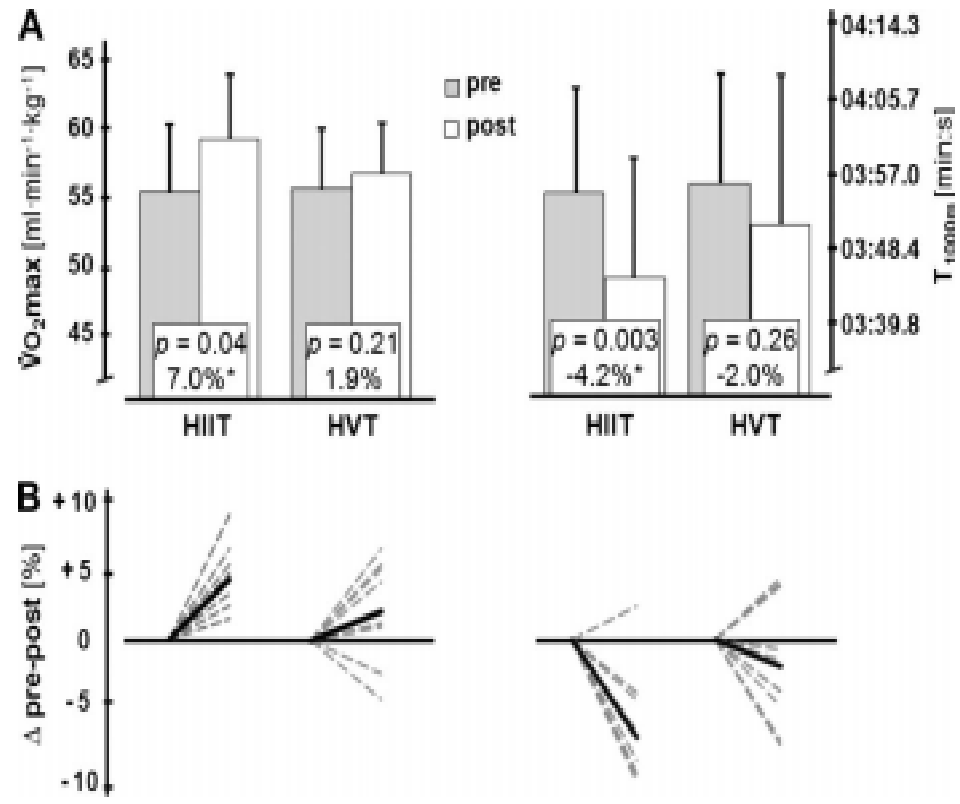

Grafik 1. (A) 5 haftalık yüksek şiddetli aralıklı antrenman (HIIT) ve yükssek hacimli antrenmanın (HVT) öncesi, sonrası, ortalama maksimal oksijen tüketim kapasitesi ve 1000m koşu zamanı değişimleri. (B) 5 haftalık yüksek şiddetli aralıklı antrenman (HIIT) ve yüksek hacimli antrenmanın (HVT) maksimal oksijen tüketim kapasitesi ve 1000m.koşu zamanı için bireysel veriler. Siyah çizgiler HIIT ve HVT için ön test ve son test verilerini temsil eder (Sperlich ve ark., 2011). 
Whyte ve ark. (2010) yapmış olduğu bir çalışmada aşırı kilolu/obez sedanter erkeklere iki hafta boyunca toplam altı seans Wingate HIIT antrenmanları uygulamışlardır. Sonuç olarak VO2 maks ve Wingate gücünün arttığı, çalışmadan 24 saat sonra insülin duyarlılığının ve istirahat yağ oksidasyon hızının daha fazla olduğu, sistolik kan basınc1 ve dinlenme karbonhidrat oksidasyonunun daha düşük olduğu gözlemlenmiştir.

Racil ve ark. (2013) obez genç kadınlara haftanın üç günü, toplam on iki hafta \%100-110 MAS (maksimal aerobik hız) şiddetinde uyguladıkları HIIT antrenmanları sonucunda vücut yağ yüzdesi, bel çevresi, total kolesterol, trigliserit ve LDL-C (düşük yoğunluklu lipoprotein) oranlarında azalma, zirve oksijen tüketiminde (VO2 $\left.{ }_{\text {pik }}\right)$ ve MAS değerlerinde artış gözlemlemişlerdir.

Obez erkeklerde interval antrenman şiddetinin yağ oksidasyonu, $\mathrm{VO} 2_{\text {pik, }}$ kan laktat seviyesi ve algılanan zorluk derecesi üzerine etkilerini inceleyen Shaea ve ark. (2013) beden kütle indeks ortalamaları $30, \pm 3,4 \mathrm{~kg} / \mathrm{m} 2$ olan on aşırı kilolu/obez erkeğe bisiklet üzerinde dört hafta boyunca haftada üç gün, $\% 90 \mathrm{VO} 2$ maks şiddetinde 30 sn çalışma ile 30 sn pasif dinlenmeyi içeren, toplam egzersiz süresi ilk hafta $30 \mathrm{dk}$ olan ve her hafta $5 \mathrm{dk}$ artan bir HIIT programı uygulamışlardır. Dört hafta sonunda $\mathrm{VO} 2_{\text {pik }}$ ve yağ oksidasyonunda artış, sabit yükte yapılan egzersiz sırasında kan laktat seviyelerinde ve algilanan zorluk derecesinde ise anlamlı bir azalma sonucuna ulaşılmıştır.

Başka bir çalışmada ise Hazell ve ark. (2014), on beş rekreasyonel aktif kadına haftada üç gün, toplam altı haftalık HIIT antrenmanı gerçekleştirmişlerdir. Antrenmanların sonucunda vücut yağında \% 8 , bel çevresinde ise \% 3,5 oranında azalma meydana gelmiştir. Bunun yanında yağsız kütle \% 1,3, maksimal oksijen tüketimi (VO2 $2_{\text {maks }}$ ) \% 8,7 ve pik koşu hızı \% 4,8 oranında artış göstermiştir.

Ojeda ve ark. (2017) yaptığı çalışmada on dört genç erkeğe \%100 maksimal aerobik hız şiddetinde, haftada iki gün sekiz hafta boyunca mekik koşusu protokolü ile HIIT uygulamışlardır. Yapılan antrenmanlar sonucunda $\mathrm{VO} 2_{\text {maks }}$ değerlerinde anlamlı artış, $20 \mathrm{~m}$ mekik koşusu zamanında anlamlı azalma meydana gelmiştir.

Aşırı kilolu kırk üç Çin'li kadın üzerinde çalışma yapan Zhang ve ark. (2015) haftada 4 gün toplam 12 hafta boyunca koşu bandında \%85-95 $\mathrm{KAH}_{\text {pik }}$ şiddetinde 4x4 dakika koşu uygulamışlardır. Setler arasında $\% 50-60 \mathrm{KAH}_{\text {pik }}$ şiddetinde 3 dakika yürüme ve 7 dakika dinlenme vermişlerdir. Ön ve son testlerin sonuçları incelendiği zaman, vücut kütlesi, beden kütle indeksi, bel ve kalça çevresi, bel-kalça oranı, vücut yăg yüzdesi, yăg kütlesi, total kolesterol, abdominal deri altı ve viseral yă̆ bölgeleri seviyelerinde anlamlı derecede azalma, $\mathrm{VO} 2_{\text {maks }}$ değerlerinde ise anlamlı derecede bir artış saptanmıştır.

Bagley ve ark. (2016) vücut kütle indeksi 24,6 olan toplam yirmi dört erkek, on yedi kadına on iki hafta süresince haftanın üç günü HIIT antrenmanı uygulamışlardır. Müdahele öncesi ve sonrası maksimum oksijen kapasitesi, yağ asidi oksidasyonu ölçülmüştür. Glikoz ve insülin değerleri de egzersiz öncesi ve sonrasında kaydedilmiştir. Antrenmanlar 4 x 20 saniye $\% 175$ VO2 $2_{\text {maks }}$ yoğunluğunda sprint döngüsü şeklinde yapılmıştır. Çalışmanın sonucunda VO $2_{\text {maks }} \% 9$ civarında artış göstermiştir. Kadınlarda bu artış daha anlamlı olmuştur. Yağ asidi oksidasyonu $\% 10$ oranında artmıştır. LDL $\% 8$ azalmış, HDL ve toplam kolesterol oranı ise $\% 6$ artmıştır. Bu egzersizin on iki haftalık sonucuna göre erkekler daha çok yağ yakarken, kadınlarda $\mathrm{VO} 2$ maks daha çok gelişme göstermiştir.

Yine Racil ve ark. (2016) on yedi obez genç kadın üzerinde haftada üç gün toplam on iki hafta \%100 maksimal aerobik HIIT antrenmanları uygulamışlardır. Sonuçlar VO2 maks artışı, vücut 


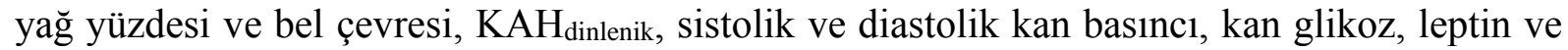
insülin değerlerinde düşüş göstermiştir (Grafik 2).

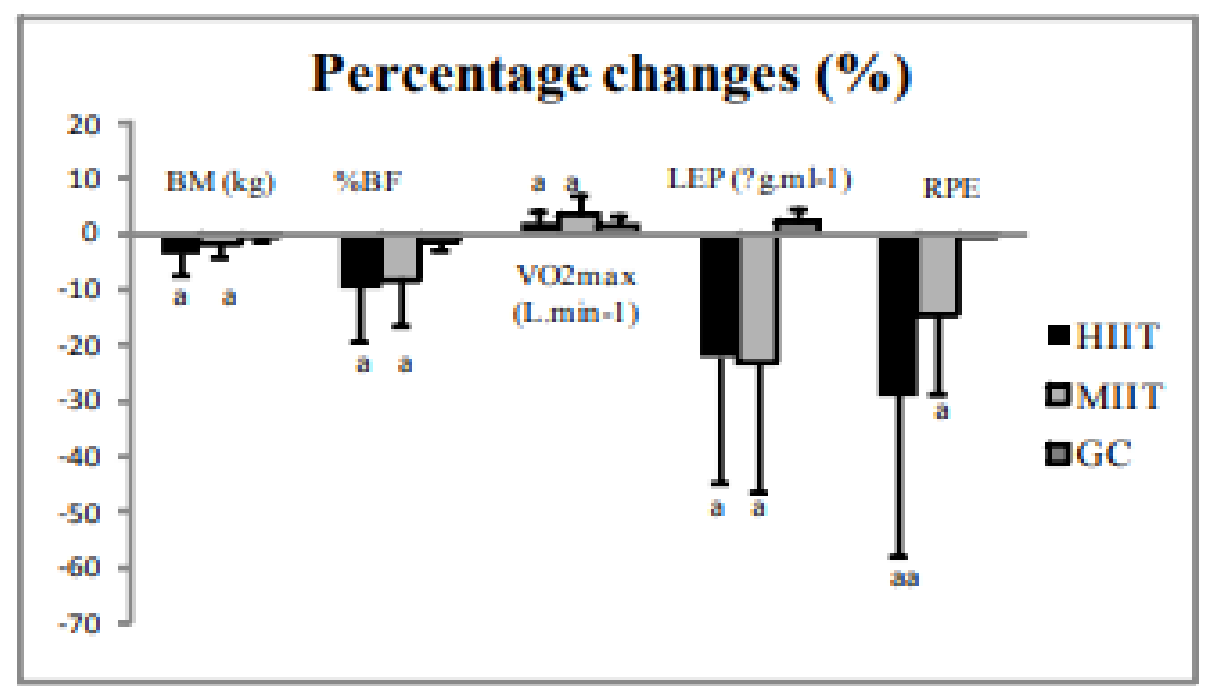

Grafik 2. Vücut kütlesi (BM), vücut yağ yüzdesi (\%BF), maksimal oksijen tüketim kapasitesi (VO2 maks), plazma leptin seviyeleri (LEP) ve zorlanma derecesinin (RPE) müdahele sonrası üç gruptaki egzersiz ile indüklenen değişimleri. GC, kontrol grubu; HIIT, yüksek şiddetli interval antrenman grubu; MIIT, orta şiddetli interval antrenman grubu. Not: Değer ortalamaları \pm SD, a (p<0,05), aa (p<0,01) (Racil ve ark., 2016).

Khammassi ve ark. (2018) 18-21 yaş aralığında yirmi obez genç katılımcıya toplam on iki hafta boyunca haftanın üç günü kalori kısıtlaması olmadan maksimal aerobik hızın \%100-110 yoğunluğunda HIIT antrenmanları yaptırmışlardır. Müdahaleden önce ve sonra aerobik kapasite, vücut kompozisyonu ve lipit profili belirlenmiştir. On iki haftanın sonunda HIIT bel çevresi, vücut kütle indeksi ve yağ kütlesi yüzdesini anlamlı olarak azaltmıştır. Maksimal

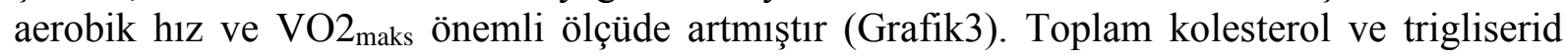
anlamlı derecede azalırken LDL ve HDL kolesterol düzeyleri değişmemiştir.
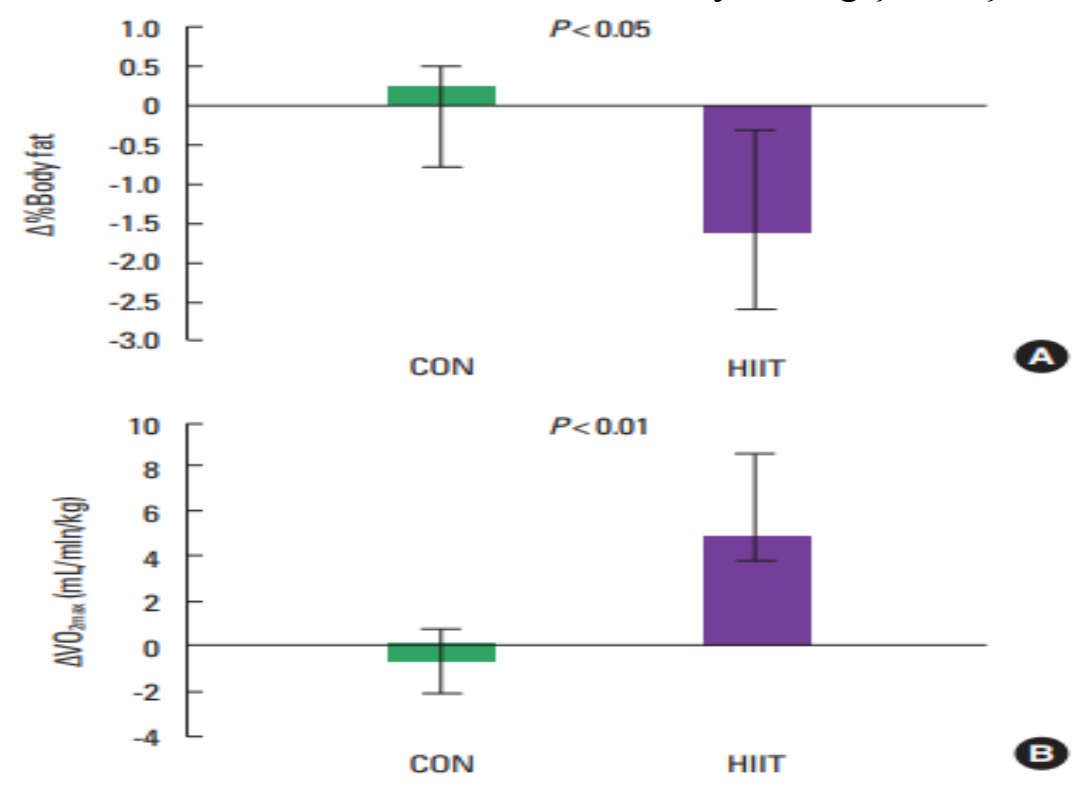

Grafik 3. İki grup arasında delta değişim farklılıkları. (A) Vücut yağ yüzdesi, (B) maksimal oksijen tüketim kapasitesi. CON, kontrol grubu; HIIT, antrenman grubu (Khammassi ve ark., 2018).

Otuz sekiz (7 erkek, 31 kadın) inaktif ve aşırı kilolu katılımcılara on iki hafta süreyle haftanın üç günü bisiklet ergometresinde HIIT egzersizi yaptıran Shelley ve ark. (2014) antrenmanların 


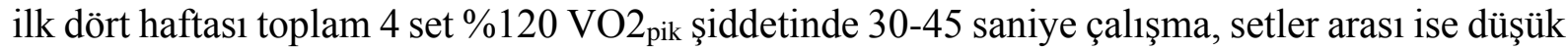
şiddette 180-120 saniye aktif dinlenme uygularken, beş ile on ikinci hafta arasında toplam 6 set $\% 120 \mathrm{VO} 2_{\text {pik }}$ şiddetinde 60 saniye çalışma, düşük şiddette 120 saniye aktif dinlenme uygulamışlardır. Sonuç olarak çalışma kapasitesinde ve $\mathrm{VO} 2_{\text {pik }}$ değerlerinde anlamlı bir artış bulunmuştur.

Yapılan başka bir çalışmada ise Alves ve ark. (2017) daha önce antrenman yapmamış yirmi kadını, uzun süreli veya kısa süreli HIIT yapmak için rastgele seçmişlerdir. Uzun süreli HIIT grubu 15 dakika'nın 1 dakikasında $\mathrm{KAH}_{\text {maks }} \% 90$ 'ında çalışmıştır. Dinlenme aralarında ise $\mathrm{KAH}_{\text {maks }} \% 60$ ' inda aktif dinlenme uygulamışlardır. Kısa süreli HIIT grubu ise 45 saniye'nin 20 saniyesinde $\mathrm{KAH}_{\text {maks }} \% 90$ 'inda çalışıp \%60 $\mathrm{KAH}_{\text {maks }}$ ' da 10 saniye aktif dinlenmişlerdir. Antrenmanlar iki grup için de haftada üç sefer olmak üzere altı hafta boyunca yapılmıştır. Her iki antrenman grubunda da antrenman sonrası yağ kütlesi, yăg yüzdesi, bel çevresi, deri kıvrımları toplamı ve algılanan zorluk derecesinde antrenman öncesine göre azalma meydana gelmiştir ve iki grupta da maksimal oksijen tüketimi artmıştır.

Aschendorf ve ark. (2018) yirmi dört genç kadın ulusal lig basketbolcusuna (yaş: 15,1 $\pm 1,1$ ) haftada iki gün toplam beş hafta $\mathrm{KAH}_{\text {maks }} \% 90-95$ 'inde basketbola özgü HIIT çalışması yapmışlardır. Katılımcılar HIIT ve kontrol grubu olarak ayrılmışlardır. HIIT grubunda YOYO dayanıklılık testi \%26,5 oranında artış göstermiştir (Grafik 4).

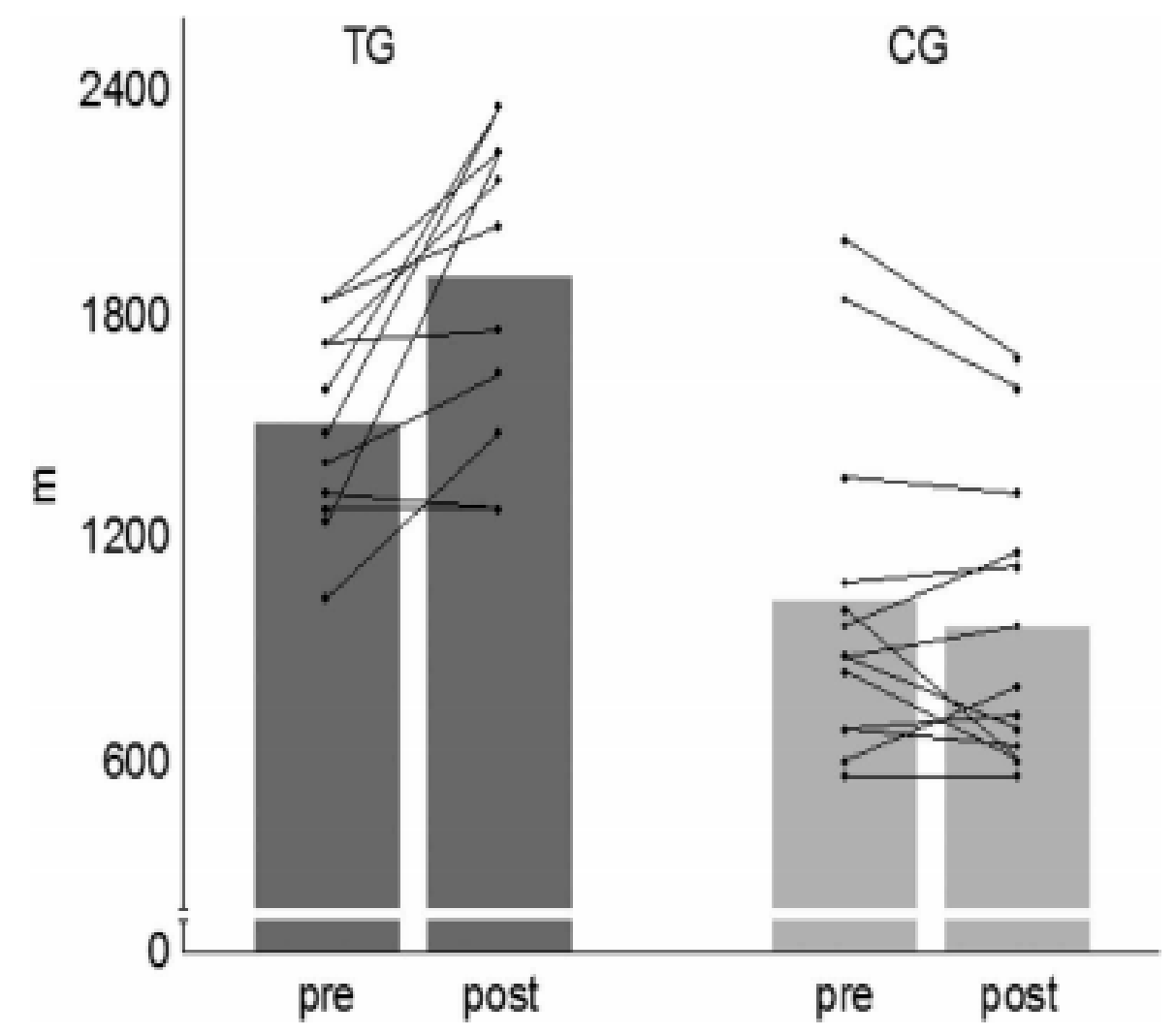

Grafik 4. Yo-yo testinde ele alınan ortalama mesafeye göre antrenman grubu (TG) ve kontrol grubu (CG) için ön test - son test sonuçları. Çubuk grafik, ortalama değerleri gösterir; çizgiler, her gruptaki katılımcılar için bireysel verileri gösterir (Aschendorf ve ark., 2018). 
Tablo 1. Aerobik dayanıklılığa ve vücut yağ yakımına etki eden bazı HIIT çalışmaları.

\begin{tabular}{|c|c|c|c|c|c|}
\hline REFERANS & $\underset{(\mathbf{n})}{\text { KATILIMCI }}$ & $\begin{array}{l}\text { ANTRENMAN } \\
\text { SEANSI / } \\
\text { SÜRESI } \\
\end{array}$ & $\begin{array}{l}\text { EGZERSİZ } \\
\text { ŞIDDDETİ }\end{array}$ & SONUÇ & \\
\hline \multirow{2}{*}{$\begin{array}{l}\text { Hazell ve } \\
\text { ark., (2014) }\end{array}$} & \multirow{2}{*}{$\begin{array}{l}15 \\
\text { rekreasyonel } \\
\text { aktif kadın }\end{array}$} & \multirow{2}{*}{3 gün / 6 hafta } & \multirow{2}{*}{$\begin{array}{l}\text { Maksimal } \\
\text { sprint }\end{array}$} & VYY ve BÇ & - \\
\hline & & & & VO2 ${ }_{\text {maks ve pik koşu hızı }}$ & + \\
\hline \multirow{2}{*}{$\begin{array}{l}\text { Khammassi } \\
\text { ve ark., } \\
(\mathbf{2 0 1 8})\end{array}$} & \multirow{2}{*}{20 obez genç } & \multirow{2}{*}{3 gün / 12 haft } & \multirow{2}{*}{$\begin{array}{l}\% 100-110 \\
\text { MAH }\end{array}$} & $\mathrm{BÇ,} \mathrm{VKİ,} \mathrm{VYY} \mathrm{ve} \mathrm{trigliserid}$ & - \\
\hline & & & & MAH ve $\mathrm{VO} 2$ maks & + \\
\hline \multirow{2}{*}{$\begin{array}{l}\text { Racil ve ark., } \\
(2013)\end{array}$} & \multirow{2}{*}{$\begin{array}{l}11 \text { obez genç } \\
\text { kadın }\end{array}$} & \multirow{2}{*}{3 gün / 12 hafta } & \multirow{2}{*}{$\begin{array}{l}\% 100-110 \\
\text { MAH }\end{array}$} & VYY, BÇ, trigliserit ve LDL & - \\
\hline & & & & $\mathrm{VO} 2_{\text {pik }}$ ve MAH & + \\
\hline $\begin{array}{l}\text { Aschendorf } \\
\text { ve ark., } \\
(\mathbf{2 0 1 8 )}\end{array}$ & $\begin{array}{l}11 \text { genç kadın } \\
\text { sporcu }\end{array}$ & 2 gün $/ 5$ hafta & $\begin{array}{l}\% 90-95 \\
\mathrm{KAH}_{\text {maks }}\end{array}$ & YOYO dayanıkl1l1k testi & + \\
\hline $\begin{array}{l}\text { Whyte ve } \\
\text { ark., (2010) }\end{array}$ & 10 obez erkek & 3 gün / 2 hafta & $\begin{array}{l}\text { Maksimal } \\
\text { wingate sprint }\end{array}$ & $\begin{array}{l}\mathrm{VO} 2_{\text {maks, }} \text { Wingate gücü ve istirahat } \\
\text { yağ oksidasyon hız1 }\end{array}$ & + \\
\hline \multirow{2}{*}{$\begin{array}{l}\text { Bagley ve } \\
\text { ark., (2016) }\end{array}$} & \multirow{2}{*}{$\begin{array}{l}24 \text { sedanter } \\
\text { erkek, } \\
17 \text { sedanter } \\
\text { kadın }\end{array}$} & \multirow{2}{*}{3 gün / 12 hafta } & \multirow{2}{*}{$\% 175 \mathrm{VO} 2_{\text {maks }}$} & VO2maks, yağ asidi oksidasyonu, HDL & + \\
\hline & & & & LDL & - \\
\hline \multirow{2}{*}{$\begin{array}{l}\text { Alves ve ark., } \\
(2017)\end{array}$} & \multirow{2}{*}{$\begin{array}{l}20 \text { sedanter } \\
\text { kadın }\end{array}$} & \multirow[b]{2}{*}{3 gün / 6 hafta } & \multirow[b]{2}{*}{$\% 90 \mathrm{KAH}_{\text {maks }}$} & $\mathrm{VO} 2_{\text {maks }}$ & + \\
\hline & & & & $\begin{array}{l}\text { YK, VYY, BÇ ve toplam deri } \\
\text { kıvrımları }\end{array}$ & - \\
\hline \multirow[b]{2}{*}{$\begin{array}{l}\text { Racil ve ark., } \\
(2016)\end{array}$} & \multirow[b]{2}{*}{$\begin{array}{l}17 \text { obez genç } \\
\text { kadın }\end{array}$} & \multirow[b]{2}{*}{3 gün/ 12 hafta } & \multirow[b]{2}{*}{$\% 100 \mathrm{MAH}$} & $\mathrm{VO} 2_{\text {maks }}$ & + \\
\hline & & & & $\begin{array}{l}\text { VK, VKİ, VYY, BÇ, sistolik-diastolik } \\
\text { kan basınc1, KAHdinlenik, kan glikoz, } \\
\text { leptin ve insülin seviyeleri }\end{array}$ & - \\
\hline \multirow{2}{*}{$\begin{array}{l}\text { Sperlich ve } \\
\text { ark., (2011) }\end{array}$} & \multirow{2}{*}{$\begin{array}{l}9 \text { genç erkek } \\
\text { sporcu }\end{array}$} & \multirow{2}{*}{13 seans / 5 hafta } & \multirow{2}{*}{$\% 90 \mathrm{KAH}_{\text {maks }}$} & $\mathrm{VO} 2_{\text {maks }}$ ve sprint & + \\
\hline & & & & $1000 \mathrm{~m}$ zaman 1 & - \\
\hline \multirow{2}{*}{$\begin{array}{l}\text { Ojeda ve } \\
\text { ark., (2017) }\end{array}$} & \multirow{2}{*}{14 genç erkek } & \multirow{2}{*}{2 gün / 8 hafta } & \multirow{2}{*}{$\% 100 \mathrm{MAH}$} & $\mathrm{VO} 2_{\text {maks }}$ & + \\
\hline & & & & 20m mekik koşusu zamanı & - \\
\hline $\begin{array}{l}\text { Impellizzeri } \\
\text { ve ark., } \\
(\mathbf{2 0 0 6 )}\end{array}$ & $\begin{array}{l}40 \text { genç } \\
\text { futbolcu }\end{array}$ & 3 gün/ 8 hafta & $\begin{array}{l}\% 90-95 \\
\mathrm{KAH}_{\text {maks }}\end{array}$ & $\begin{array}{l}\text { VO2 maks, bireysel anaerobik eşik ve } \\
\text { Ekblom testi }\end{array}$ & + \\
\hline \multirow{2}{*}{$\begin{array}{l}\text { Trapp ve } \\
\text { ark., (2008) }\end{array}$} & & än 15 bo & Maksimal & Deri altı yağ oranı, VK & - \\
\hline & 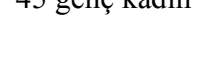 & $J$ guil/ IJ Ilaila & Sprint & VO2 $2_{\text {maks, }}$ insülin duyarlılığ 1 & + \\
\hline Shaea ve & & & & VO2 $2_{\text {pik}}$, yağ oksidasyonu & + \\
\hline ark., $(2013)$ & 10 obez erkek & 3 gün / 4 hafta & $\% 90 \mathrm{VO} 2_{\text {maks }}$ & $\begin{array}{l}\text { Kan laktat seviyesi, Algilanan zorluk } \\
\text { derecesi }\end{array}$ & - \\
\hline $\begin{array}{l}\text { Shelley ve } \\
\text { ark., (2014) }\end{array}$ & $\begin{array}{l}38 \text { aşırı kilolu } \\
\text { katılımcı }\end{array}$ & 3 gün / 12 hafta & $\% 120 \mathrm{VO} 2_{\text {pik }}$ & Çalışma kapasitesi ve VO2 $2_{\text {pik }}$ & + \\
\hline Zhang ve & & & & $\mathrm{VO} 2$ maks & + \\
\hline ark., (2015) & 43 kadın & 4 gün / 12 hafta & $\% 85-95 \mathrm{KAH}_{\text {pik }}$ & $\begin{array}{l}\text { VK, VKİ, BKÇ, VYY, abdominal deri } \\
\text { altı ve viseral yağ }\end{array}$ & - \\
\hline
\end{tabular}




\section{TARTIŞMA VE SONUÇ}

HIIT, yüksek şiddetli yüklenmelerin aralarına toparlanma süreçlerinin serpiştirildiği kısa süreli bir antrenman yöntemi olup fizyolojik mekanizmayı uzun süreli orta ve düşük şiddetteki egzersizlerden daha fazla uyarmaktadır. Sportif performans ve sağlık gelişimi, ekonomik zaman özelliği ve egzersiz çeşitliliği bakımından oldukça popüler bir antrenman haline gelmiştir. Akgül ve ark., (2016) tarafından kadınlar üzerinde yapılan bir araştırmada, sadece 2 hafta toplam 6 seans HIIT antrenmanları uygulanmıştır. Çalışmanın sonucunda VO2 ${ }_{\text {maks, }}$ VO2 $2_{\text {pik }}$ ve tükenme zamanı gibi aerobik göstergelerde anlamlı gelişmeler saptanmıştır. Mevcut derlemede sporcu, sedanter, obez ve aşırı kilolu bireylerde HIIT'in vücut yağ yakımı ve aerobik dayanıklılık üzerindeki potansiyel etkileri incelenmiştir. Derlemeye dahil edilen 15 çalışmada HIIT antrenmanlarının vücut yağ oranı ve aerobik dayanıklılık üzerindeki etkileri ortaya konulmuştur (Tablo 1). HIIT fizyolojik etki mekanizması ile kısa sürede dayanıklılık gelişiminde önemli sonuçlar ortaya çıkarabilmektedir. Ayrıca geleneksel uzun süreli düşük şiddetli egzersizlere kıyasla daha fazla vücut yağ yakımına sebep olabilmektedir (Buchheit ve Laursen, 2013). HIIT antrenmanlarında uygulanan yöntemler farkl1lık gösterse de (bisiklet, koşu, saha temelli) sonuçlar, bireylerin aerobik dayanıklılık özelliklerini önemli ölçüde geliştirdiğini göstermektedir (Ojeda ve ark., 2017; Sperlich ve ark., 2011; Whyte ve ark., 2010).

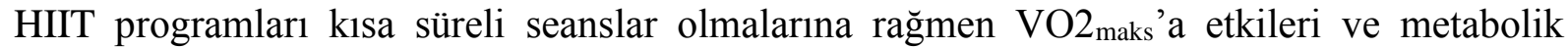
faydaları oldukça tatmin edicidir. Ayrıca HIIT ile ilişkili olarak geliştirilmiş aerobik kapasite ve bel çevresi yağlarının azalmasının yanı sıra total kolesterol, trigliserid, sistolik-diastolik kan basınc1, kan glikozu, leptin ve insülin seviyeleri oranlarında da azalma bildirilmiştir (Khammassi ve ark., 2018; Racil ve ark., 2013; Zhang ve ark., 2015).

Yüksek şiddetli interval antrenmanların vücut yağ yakım hızı ve vücut yağ kütlesi azalma oranları bakımından incelendiğinde önemli bir antrenman stratejisi olduğu görülmektedir. Yağ yakımı indüklemek için uygulanan antrenmanlarda uzun süren düşük tempoda yürümek, koşmak vb. düzenli egzersizlere odaklanılmıştır. Ancak bu tür egzersizler uzun süreler sonunda kilo kaybına neden olmuştur. Bu yüzden vücut yağ oranını daha etkili ve daha kısa sürede azaltan egzersiz arayışları başlamıştır. İncelenen bulgularda HIIT'in bu ihtiyacı karşılayabilecek zaman açısından ekonomik ve etkili bir antrenman olduğu görülmektedir. Bagley ve ark. (2016) tarafından yapılan bir çalışmada HIIT antrenmanları yoluyla erkeklerin $(1,3 \mathrm{~kg})$ kadınlara $(0,6 \mathrm{~kg})$ göre daha çok yağ yaktığı gözlemlenmiş ve yağ asidi oksidasyonu $\% 10$ oranında artmıştır. Bu çalışmadan yola çıkarak kadınların ve erkeklerin fizyolojik olarak bazı farklılıklara sahip olması yapılan HIIT antrenmanlarına verilen fizyolojik cevapları etkileyebileceği düşünülebilir. Ancak bu konuda net bir bilgiye ulaşmak için daha çok araştırmaya ihtiyaç vardır. Gelecek araştırmalarda HIIT' in farklı cinsiyetlerde meydana getireceği sonuçlar incelenebilir.

Literatürü incelediğimiz zaman yetişkinlerde HIIT'in olumlu etkilerini ortaya koyan birçok çalışma olmasına rağmen çocuklar ve gençler üzerinde yapılan çalışma sayısı oldukça sınırlı kalmıştır (Greig ve ark., 2014). Engel ve ark. (2018) yaptıkları araştırmada, bazı çalışmaların

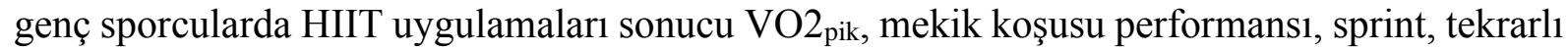
sprint ve sıçrama performansında olumlu gelişmeler sağlandığını belirtmişlerdir. Derlediğimiz çalışmalarda gençlerde gözlemlenen HIIT sonuçları, yetişkinlerde gözlemlenen sonuçlar ile paralellik göstermektedir. Çocuklar ve gençler üzerinde yapılan sınırlı sayıda çalışma olmasına rağmen sportif performansı ve genel sağlığı iyileştirici etkileri gösteren çalışmalar mevcuttur. HIIT özellikle aşırı kilolu / obez gençlerde vücut kompozisyonu, kondisyon ve lipit profilini geliştirmede, metabolik ve kardiyovasküler komplikasyonların riskini azaltmada etkili bir yöntem olarak kullanılabilmektedir (Len Kravitz, 2011; Martins ve ark., 2016). Ayrıca HIIT genç sporcuların antrenmanlarında, spora özel yeteneklerin yanı sıra teknik ve taktik becerilerin 
geliştirilmesi için yeterli zaman bırakırken, performansı arttırmak için zaman açısından verimli ve uygun bir antrenman metodu olabilmektedir.

Yapılan çalışmalar sonucunda HIIT'in sağlık belirteçlerinde iyileşme gerçekleştirmesi için

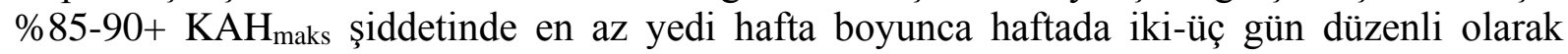
uygulanması önerilmektedir. Ayrıca HIIT antrenmanları şiddeti yüksek yüklenmeler içerdiği için bireyler uygulanacak program öncesinde mutlaka tıp hekimleri tarafından kontrolden geçmeli ve antrenmanlar uzman antrenörler tarafından planlanmalıdır. Sonuç olarak mevcut derlemenin bulgularında HIIT antrenmanlarına katılan bireyler ile kontrol grupları karşılaştırıldığında, HIIT antrenmanlarının aerobik dayanıklılıkta ve vücut yağ yakım oranlarında önemli gelişmeler ortaya koyduğu tespit edilmiştir.

\section{KAYNAKLAR}

Akgül M.S., Gürses V.V., Karabıyık H., Koz M. (2016). İki haftalık yüksek şiddetli interval antrenmanın kadınların aerobik göstergeleri üzerine etkisi. International Journal of Science Culture and Sport, 2148-1148.

Alves E.A., Salermo G.P., Panissa V.L.G., Franchini E., Takito E.Y. (2017). Effects of long or short duration stimulus during high-intensity interval training on physical performance, energy intake, and body composition. Journal of Exercise Rehabilitation, 13(4), 393-399.

American College of Sports Medicine (2014). Information on high-intensity interval training. ACSM's Consumer Information Committee.

Aschendorf P.F., Zinner C., Delextrat A., Engelmeyer E., Mester J. (2018). Effects of basketball-specific highintensity interval training on aerobic performance and physical capacities in youth female basketball players. The Physician and Sportsmedicine, 1, 65-70.

Aslan, N, Yardımcı, H. (2017). Obezite üzerine etkili yeni bir hormon: İrisin. Gümüşhane Üniversitesi Sağllk Bilimleri Dergisi, 6(3), 176-183.

Babraj J.A, Vollaard N.B, Keast C, Guppy F.M, Cottrell G, Timmons J.A. (2009). Extremely short duration highintensity interval training substantially improves insulin action in young healthy males. BMC Endocrine Disorders, 9(3),18-22.

Bagley, L., Slevin, M., Bradburn, S., Liu, D., Murgatroyd, C., Morrissey, G., Carroll, M., Piasecki, M., Gilmore, W. S., \& McPhee, J. S. (2016). Sex differences in the effects of 12 weeks sprint interval training on body fat mass and the rates of fatty acid oxidation and $\mathrm{VO}_{2} \max$ during exercise. BMJ open sport \& exercise medicine, 2(1), e000056. https://doi.org/10.1136/bmjsem-2015-000056

Buchheit M, Laursen P.B. (2013). High-intensity interval training solutions to the programming puzzle: Part I: cardiopulmonary emphasis. Sports Med, 43(5), 313-338.

Castillo-Quan J. I. (2012). From white to brown fat through the PGC-1 $\alpha$-dependent myokine irisin: implications for diabetes and obesity. Disease models \& mechanisms, 5(3), 293-295. https://doi.org/10.1242/dmm.009894

Costigan, S. A., Eather, N., Plotnikoff, R. C., Taaffe, D. R., \& Lubans, D. R. (2015). High-intensity interval training for improving health-related fitness in adolescents: a systematic review and meta-analysis. British journal of sports medicine, 49(19), 1253-1261. https://doi.org/10.1136/bjsports-2014-094490

Engel F.A, Ackermann A, Chtourou H, Sperlich B. (2018) High-intensity interval training performed by young athletes: A systematic review and meta-analysis. front. Physiol, 9, 1012.

Gibala, M. J., \& McGee, S. L. (2008). Metabolic adaptations to short-term high-intensity interval training: a little pain for a lot of gain?. Exercise and sport sciences reviews, 36(2), 58-63. https://doi.org/10.1097/JES.0b013e318168ec1f 
Gibala, M. J., McGee, S. L., Garnham, A. P., Howlett, K. F., Snow, R. J., \& Hargreaves, M. (2009). Brief intense interval exercise activates AMPK and p38 MAPK signaling and increases the expression of PGC-1alpha in human skeletal muscle. Journal of applied physiology (Bethesda, Md.: 1985), 106(3), 929-934. https://doi.org/10.1152/japplphysiol.90880.2008

Gizaw, M., Anandakumar, P., \& Debela, T. (2017). A review on the role of 1risin in 1nsulin resistance and type 2 diabetes mellitus. Journal of pharmacopuncture, 20(4), 235-242.

Gökdemir K., Koç H., Yüksel O. (2007). Aerobik antrenman programının üniversite örencilerinin bazı solunum ve dolaşım parametreleri ile vücut yağ oranı üzerine etkisi. SDÜ Egzersiz, 1(1).

Greig R.M., Harris N., Duncan S., Schofield G. (2014). A review of adolescent high-1ntensity interval training. Sports Medicine, 44(8), 1071-1085.

Gündüz N. (1997). Antrenman Bilgisi. Saray Kitapevi, İzmir.

Hazell TJ., Hamilton CD., Olver TD., Lemon WR. (2014). Running sprint interval training induces fat loss in women. Applied Physiology Nutrition and Metabolism, 39(8), 1-7.

Impellizzeri F.M., Marcora S.M., Castagna C., Reilly T., Sassi A., Iaia F.M., Rampinini E. (2006). Physiological and performance effects of generic versus specific aerobic training in soccer players. Int J Sports Med, 27(6), 48392.

Khammassi M., Nejmeddine O., Sameh H.T., Moncef F., David T., Anissa B. (2018). Impact of a 12-week highintensity interval training without caloric restriction on body composition and lipid profile in sedentary healthy overweight/obese youth. Journal of Exercise Rehabilitation, 14(1), 118-125.

Len Kravitz. (2011). High-1ntensity interval training. American College of Sports Medicine, Brochure.

Little, J.P. (2010). A practical model of low- volume high- intensity interval training induces mitochondrial biogenesis in human skeletal muscle: potential mechanisms. J Physiol, 588, 1011-1022.

Logan, G. R., Harris, N., Duncan, S., \& Schofield, G. (2014). A review of adolescent high-intensity interval training. Sports medicine (Auckland, N.Z.), 44(8), 1071-1085. https://doi.org/10.1007/s40279-014-0187-5

Martins C., Kazakova I., Ludviksen M., Mehus I., Wisloff U., Kulseng B., Morgan L., King N. (2016). Highintensity interval training and isocaloric moderate-1ntensity continuous training result in similar improvements in body composition and fitness in obese individuals. International Journal of Sports Nutrition and Exercise Metabolism, (3), 197-204.

Norheim, F., Langleite, T. M., Hjorth, M., Holen, T., Kielland, A., Stadheim, H. K., Gulseth, H. L., Birkeland, K. I., Jensen, J., \& Drevon, C. A. (2014). The effects of acute and chronic exercise on PGC-1 $\alpha$, irisin and browning of subcutaneous adipose tissue in humans. The FEBS journal, 281(3), 739-749. https://doi.org/10.1111/febs.12619

Ojeda A.H., Maliqueo S.G., Guerra M.C., Fuentes G.B., Villanueva T.R., Serrano P.C. (2017). Effects of a high intensity interval training on the aerobic capacity of adolescents. Rev Med Chile, 145, 972-979.

Patlar S., Sanioğlu A., Kaplan T., Polat Y. (2003). Futbolcularda sürekli koşular metodu ile oyun formu metodunun dayanıklılık parametreleri üzerine etkisi. SÜ Beden Eğitimi ve Spor Bilim Dergisi, 5(1-2), 10-17.

Perakakis, N., Triantafyllou, G. A., Fernández-Real, J. M., Huh, J. Y., Park, K. H., Seufert, J., \& Mantzoros, C. S. (2017). Physiology and role of irisin in glucose homeostasis. Nature reviews. Endocrinology, 13(6), 324-337. https://doi.org/10.1038/nrendo.2016.221

Racil G., Coquart J.B., Elmontassar W., Haddad M., Goebel R., Chaouachi A., Amri M., Chamari K. (2016). Greater effects of high- compared with moderate-intensity interval training on cardio-metabolic variables, blood leptin concentration and ratings of perceived exertion in obese adolescent females. Biol Sport, 33(2), $145-152$. 
Racil G., Ounis BO., Hammouda O., Kallel A., Zouhal H., Chamari K., Amri M. (2013). Effects of high vs. moderate exercise intensity during interval training on lipids and adiponectin levels in obese young females. Eur J Appl Physiol, 113, 2531-2540.

Rana, J. S., Li, T. Y., Manson, J. E., \& Hu, F. B. (2007). Adiposity compared with physical inactivity and risk of type 2 diabetes in women. Diabetes care, 30(1), 53-58. https://doi.org/10.2337/dc06-1456

Reddigan, J. I., Ardern, C. I., Riddell, M. C., \& Kuk, J. L. (2011). Relation of physical activity to cardiovascular disease mortality and the influence of cardiometabolic risk factors. The American journal of cardiology, 108(10), 1426-1431. https://doi.org/10.1016/j.amjcard.2011.07.005

Revan S., Balcı Ş.S., Pepe H., Aydoğmuş M., (2008). Sürekli ve internal koşu antrenmanlarının vücut kompozisyonu ve aerobik kapasite üzerine etkileri. Spormetre Beden Ĕgitimi ve Spor Bilimleri Dergisi, 6(4), 193197.

Schumacher, M. A., Chinnam, N., Ohashi, T., Shah, R. S., \& Erickson, H. P. (2013). The structure of irisin reveals a novel intersubunit $\beta$-sheet fibronectin type III (FNIII) dimer: implications for receptor activation. The Journal of biological chemistry, 288(47), 33738-33744. https://doi.org/10.1074/jbc.M113.516641

Shaea A.A., Neil A.K., Andrew P.H., Nuala M.B. (2013). Effect of interval training intensity fat oxidation blood lactate and the rate of perceived exertion in obese men. Springer Plus, 2, 532.

Shelley E., Elizabeth A., Helen T., James A., Amanda S., Ian D., Nathan A. (2014). Continuous exercise but not high-1ntensity interval training improves fat distribution in overweight adults. Hindawi Publishing Corporation Journal of Obesity, 834865.

Sperlich B., De Mare' Es M., Koehler K., Linville J., Holmberg H.C., Mester J. (2011). Effects of 5 weeks of highintensity interval training vs. volume training 14-year-old soccer players. Journal of Strength and Conditioning Research, 25(5), 1271-1278.

Trapp E. G., Chisholm D.J., Freund J., Boutcher, S. H. (2008). The effects of high- intensity intermittent exercise training on fat loss and fasting insulin levels of young women. International Journal of Obesity, 32, 684-691.

Weston, K. S., Wisløff, U., Coombes, J. S. (2014). High-intensity interval training in patients with lifestyleinduced cardiometabolic disease: A systematic review and meta-analysis. British journal of sports medicine, 48(16), 1227-1234. https://doi.org/10.1136/bjsports-2013-092576

Whyte LJ., Jason M.R., Gill A., Cathcart, J. (2010). Effect of 2 weeks of sprint interval training on health-related outcomes in sedentary overweight/obese men. Metabolism: clinical and experimental, 59(10), 14218

Zabinski, M. F., Saelens, B. E., Stein, R. I., Hayden-Wade, H. A., Wilfley, D. E. (2003). Overweight children's barriers to and support for physical activity. Obesity research, 11(2), $238-246$. https://doi.org/10.1038/oby.2003.37

Zhang H., Tom KT., Weifeng Q., Jingjing W., Jinlei N., Yuxiu H. (2015). Effect of high-intensity interval trainıng protocol on abdominal fat reduction in overweight chinese women: A randomized controlled trial. Kinesiology, 47(1), 57-66 